\title{
MICROALBUMINURIA IS THE EARLIEST PREDICTIVE MARKER FOR MICROVASCULAR COMPLICATIONS AND CARDIOVASCULAR RISK IN PATIENTS WITH DIABETES, A RANDOMIZED STUDY CONDUCTED IN RURAL POPULATION OF BANKURA DISTRICT, WEST BENGAL.
}

Debkumar Ray, Debabrata Nandy, Sudipta Bhattacharyya, Somnath Patra, Sumana Ray.

1. Assistant Professor, Department of Biochemistry, B. S. Medical College, Bankura, West Bengal.

2. Associate Professor, Department of Radiology, MMC. Midnapur. West Bengal

3. Associate Professor, Department of Pathology, Burdwan Medical College. Burdwan, West Bengal.

4. Research Associate, B. S. Medical College, Bankura, West Bengal.

5. Research Associate, B. S. Medical College, Bankura, West Bengal.

\section{CORRESPONDING AUTHOR}

Dr. Debkumar Ray,

KL-1, Jagatpur, Ganga-Yamuna Apartment,

Block-B, Flat: B/C\&D,

Ashwininagar,Kolkata-700059

E-mail: dr.debkumar@gmail.com,

Phone: 00919476233354.

ABSTRACT: Diabetic nephropathy is one of the major microvascular complications in both type 1 and type 2 diabetes. It is also a risk factor for development of macrovascular complications including atherosclerosis, myocardial infarction, cerebrovascular accident (CVA) and peripheral vascular diseases. A randomized study conducted on diabetic $(n=40)$ with an age group between 40 to 70 years, where non-diabetic $(n=35)$ was control. Fischer's unpaired " $t$ test" was the analytical tool for the study and which shows 24 hours urine microalbumin and creatinine as well as microalbumin/creatinine ratio in diabetic was significantly altered as compared with non-diabetic control, where the p-value is $<0.001$.Altered lipid metabolism in diabetic was evaluated by measuring total cholesterol, triglyceride, LDL-C. Statistical analysis showed remarkable elevation of all above and the p-value was $<0.001$,and was significant. The study revealed some deleterious microvascular changes in diabetes and imposes cardiovascular risk.

KEY WORDS: Microalbuminuria, Diabetic nephropathy, Cardiovascular risk

INTRODUCTION: As per World Health Organization (WHO),at least 171 million people suffering worldwide in diabetes. Its incidence is increasing rapidly, and estimated that by the year 2030, this number will be double. Diabetes mellitus occurs throughout the world, but is more common (type II) in developed countries. The greatest increase in prevalence is, however expected to occur in Asia and Africa. The increase in incidence of diabetes in developing countries follows the trend of urbanization and lifestyle changes, perhaps most importantly a western style diet. This suggests an environmental (dietary) effect, but there is little understanding of the mechanism(s) at present, though there is much speculation, some of it most compellingly presented (1).

India leads the world with largest number of diabetic subjects earning the dubious distinction of being termed "the diabetes capital of the world". According to the diabetes atlas 2006 published by the International Diabetes Federation ,the number of people with diabetes in 
India currently around 40.9 million is expected to rise to 69.9 million by 2025 unless urgent preventive steps taken. The so called "Asian Indian Phenotype" refers to certain unique biochemical abnormalities in Indians which include increased insulin resistance, greater abdominal adiposity i.e., higher waist circumference despite lower body mass index, lower adiponectin and higher high sensitive C-reactive protein levels. This phenotype makes Asian Indians more prone to diabetes and premature coronary artery disease (12). At least a part of this is due to genetic factors; however the primary modulator of the epidemic of diabetes is the rapid epidemiological transition associated with changes in dietary patterns and decreased physical activity as evident from the higher prevalence of diabetes in the urban population. Even though the prevalence of microvascular complications of diabetes like retinopathy and nephropathy are comparatively lower in Indians, the prevalence of premature coronary artery disease is much higher in Indians compared to other ethnic group(2).In diabetes glucose is underutilized and develops clinical hyperglycemic episodes, such as ketoacidosis or hyperosmolar coma. As the disease progresses individuals are at risk for the development of specific complications including retinopathy leading to blindness, nephropathy causes renal failure and atherosclerotic heart disease(3).We have carried out the study in Department of Biochemistry in association with Department of Medicine ,B.S. Medical College \& Hospital, Bankura, WB, India,

MATERIALS AND METHODS: Fourty $(n=40)$ diabetic for the study and thirty five $(n=35)$ non diabetic for control selected randomly with the age group between 40 to 70 years, where male female ratio was 1:1.During selection of the study group, the stages of chronic kidney diseases (CKD) and cardiac functions in relation of dyslipidemia was evaluated. Occupations ,Body Mass Index (BMI),smoking habit and dietary intake was noted for individuals. The study was conducted in Department of Biochemistry in association with Department of Medicine, B.S. Medical College \& Hospital, Bankura, West Bengal.

\section{Inclusion and exclusion criteria for the selection of Diabetic and Non-Diabetic individual (study and control group)}

\begin{tabular}{|l|l|c|}
\hline & \multicolumn{1}{|c|}{ Inclusion criteria } & Exclusion criteria \\
\hline 1. & Ages between 40-70 years & Pregnancy with diabetes \\
\hline 2. & Type I/Type II Diabetes more than ten years & \multirow{2}{*}{} \\
\hline 3. & $\begin{array}{l}\text { Uncontrolled diabetes with or without oral } \\
\text { hypoglycemics or insulin with monthly } \\
\text { follow up }\end{array}$ & \\
\cline { 1 - 2 } 4. & Impaired renal functions \\
\cline { 1 - 2 } 5. & Diabetes with altered cardiac profile & \multicolumn{1}{|c}{} \\
\hline
\end{tabular}

The following biochemical parameters are estimated in study and control populations: 24 hours urine collected for microalbumin and creatinine estimation. Microalbumin determined by turbidimetric method (Synchron CX System) $(4,6,9)$ and expressed in mg/24 hours urine and creatinine by alkaline picrate method and expressed in $\mathrm{mg} / \mathrm{dl}$. Fasting blood sample collected for the assay of cholesterol, triglyceride and HDL determined by enzymatic method and expressed in $\mathrm{mg} / \mathrm{dl}$. LDL cholesterol calculated by using the formula (3). 
Statistical analysis is being done by Fischer's unpaired "t-test", where study group consists of fourty $(n=40)$ and thirty five $(n=35)$ cases in control group.

RESULTS:Table-1 Different parameters and estimated Mean \pm SD values in Diabetic study group $(n=40)$ and Non-Diabetic control group $(n=35)$

\begin{tabular}{|l|c|c|}
\hline \multicolumn{1}{|c|}{ Parameters } & Diabetic(Study Group) & Non-Diabetic (Control Group) \\
\hline $\begin{array}{l}\text { Microalbumin(mcg/24hrs } \\
\text { urine), Mean } \pm \text { SD }\end{array}$ & $4888.35 \pm 326^{*}$ & $164 \pm 64$ \\
\hline $\begin{array}{l}\text { Creatinine(mg/24hrs urine), } \\
\text { Mean } \pm \text { SD }\end{array}$ & $38.13 \pm 2.79^{*}$ & $12.5 \pm 0.86$ \\
\hline $\begin{array}{l}\text { Microalbumin/Creatinine ratio } \\
\text { (mcg/mg) Mean } \pm \text { SD }\end{array}$ & $142.93 \pm 17.69^{*}$ & $12.74 \pm 0.80$ \\
\hline $\begin{array}{l}\text { Serum Cholesterol(mg/dl), } \\
\text { Mean } \pm \text { SD }\end{array}$ & $318.7 \pm 5.99^{*}$ & $209.7 \pm 5.21$ \\
\hline $\begin{array}{l}\text { Serum Triglyceride } \\
\text { (mg/dl), Mean } \pm \text { SD }\end{array}$ & $200.95 \pm 4.42^{*}$ & $115.3 \pm 10.92$ \\
\hline $\begin{array}{l}\text { Serum HDL-C l(mg/dl), } \\
\text { Mean } \pm \text { SD }\end{array}$ & $55.15 \pm 0.93^{*}$ & $110.04 \pm 5.28$ \\
\hline $\begin{array}{l}\text { Serum LDL-C (mg/dl), } \\
\text { Mean } \pm \text { SD }\end{array}$ & $223.36 \pm 5.49^{*}$ & \\
\hline
\end{tabular}

${ }^{*} \mathrm{p}$ value $<0.001$

Figure-1 Diagram represents microalbumin (mcg/24hours of urine) level in diabetic (study) and non-diabetic (control) group.

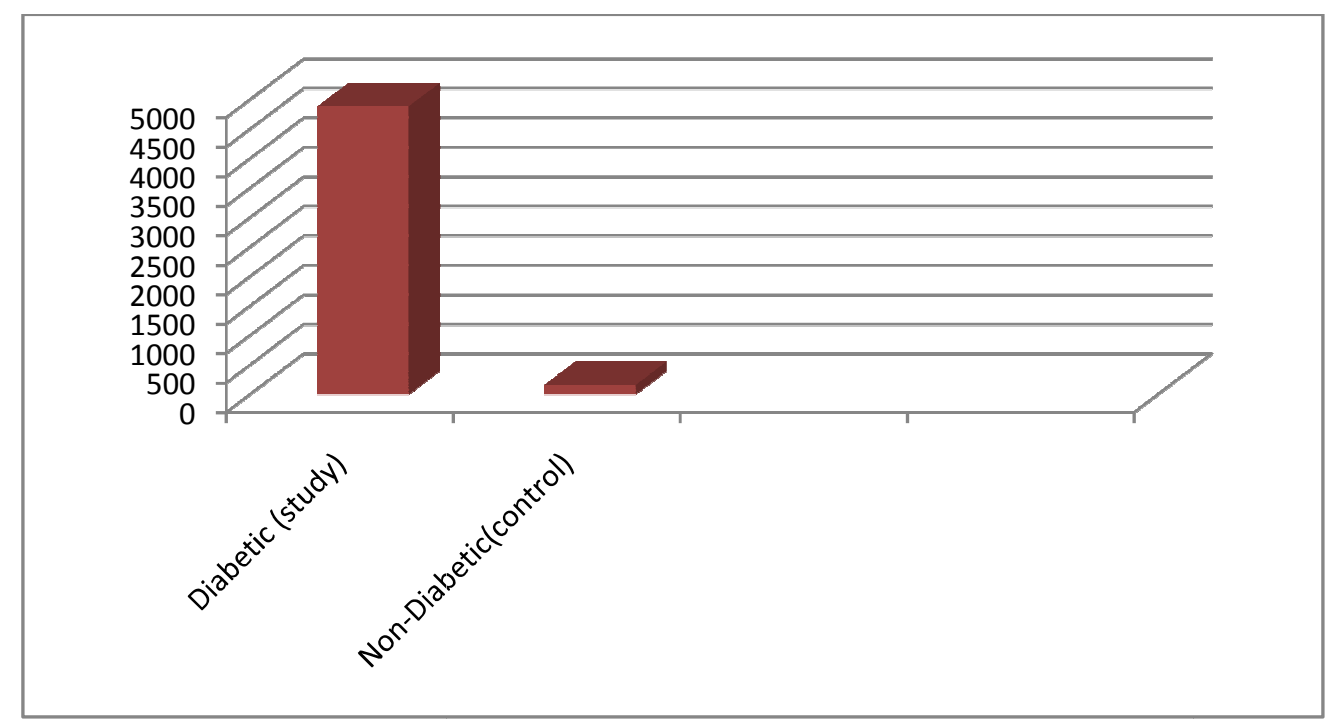


Figure-2 Diagram represents creatinine ( $\mathrm{mg} / 24$ hours of urine) level in diabetic (study) and non-diabetic (control) group.

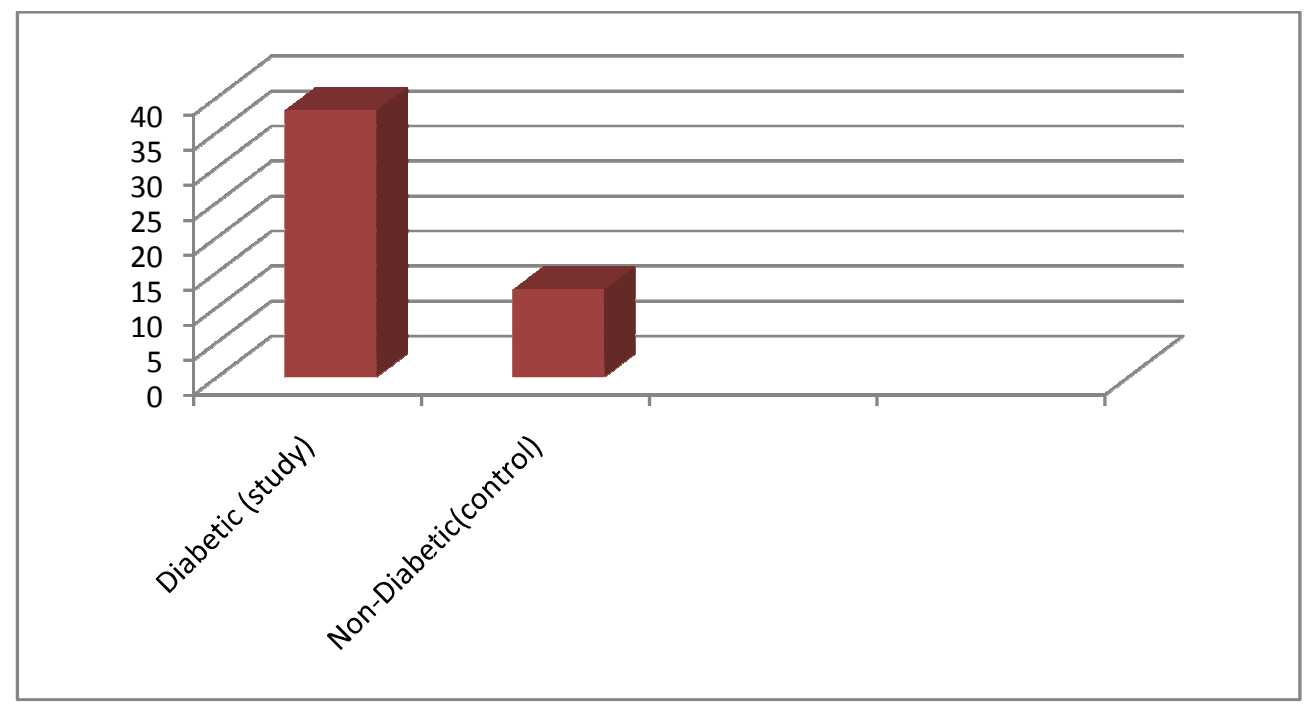

Figure-3 Diagram represents Microalbumin/creatinine ratio ( $\mathrm{mcg} / \mathrm{mg}$ ) level in diabetic (study) and non-diabetic (control) group.

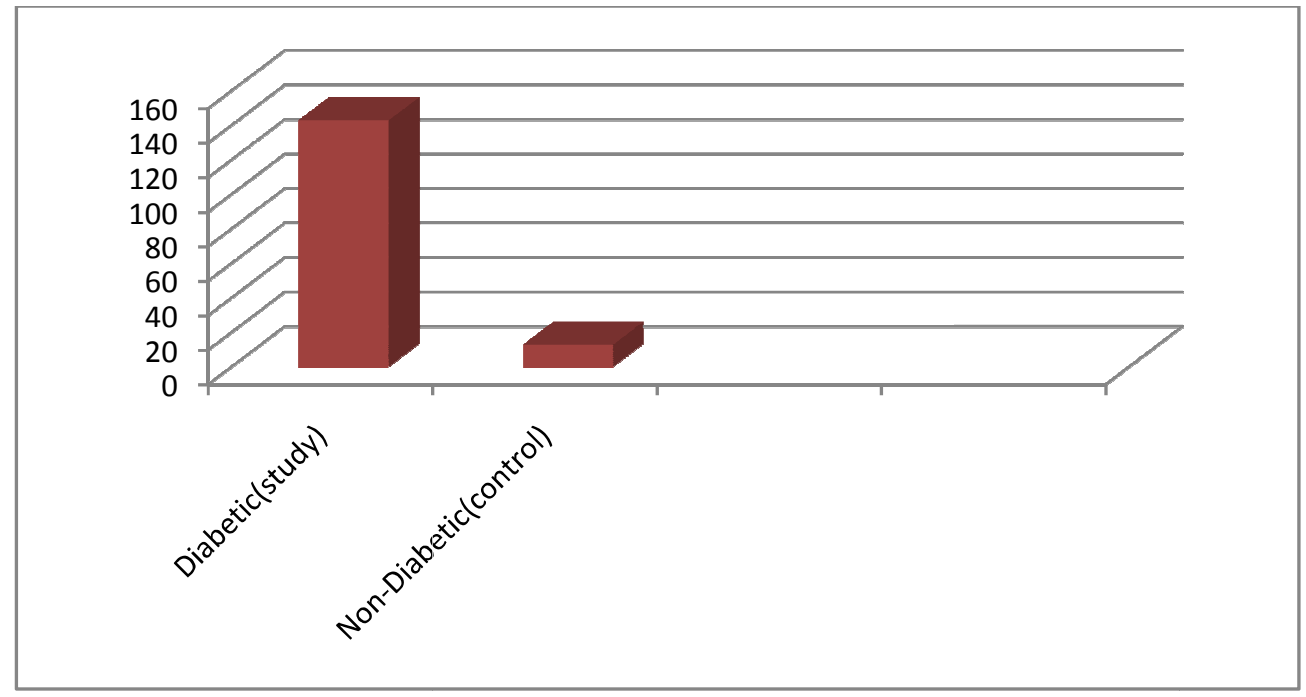


Figure-4 Diagram represents serum Cholesterol (mg/dl) level in diabetic (study) and nondiabetic (control) group.

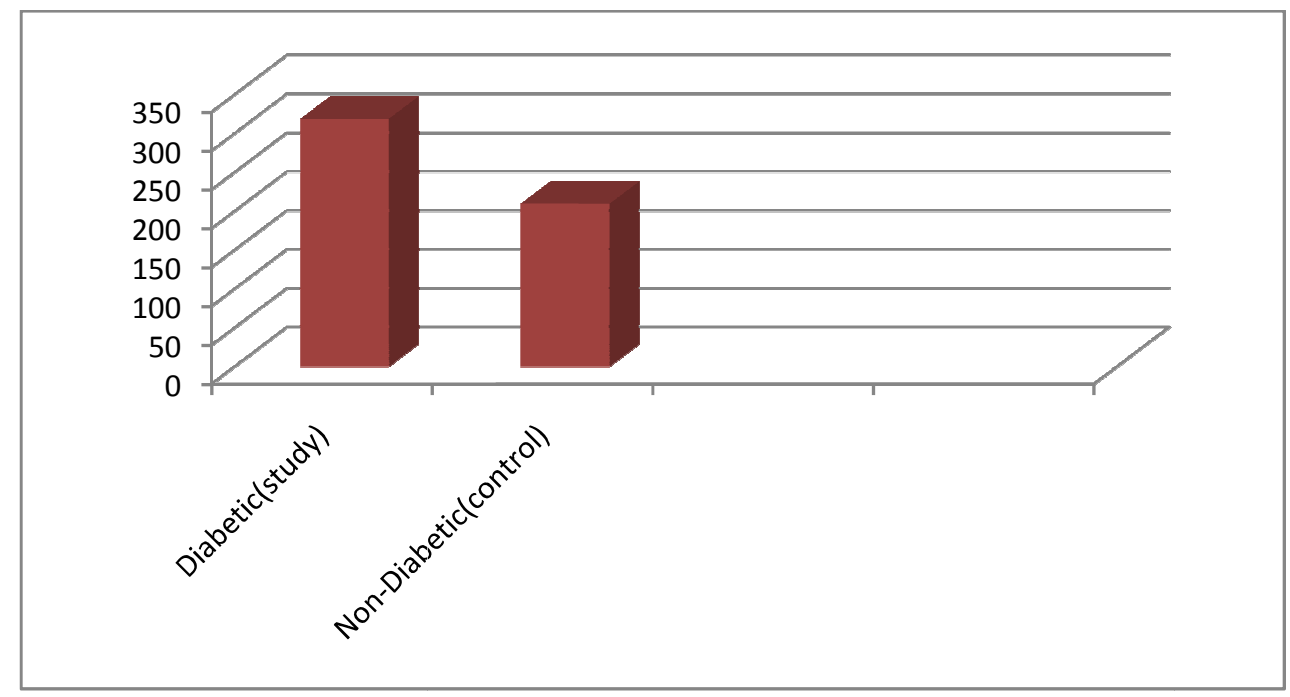

Figure-5 Diagram represents serum Triglyceride (mg/dl) level in diabetic (study) and nondiabetic (control) group.

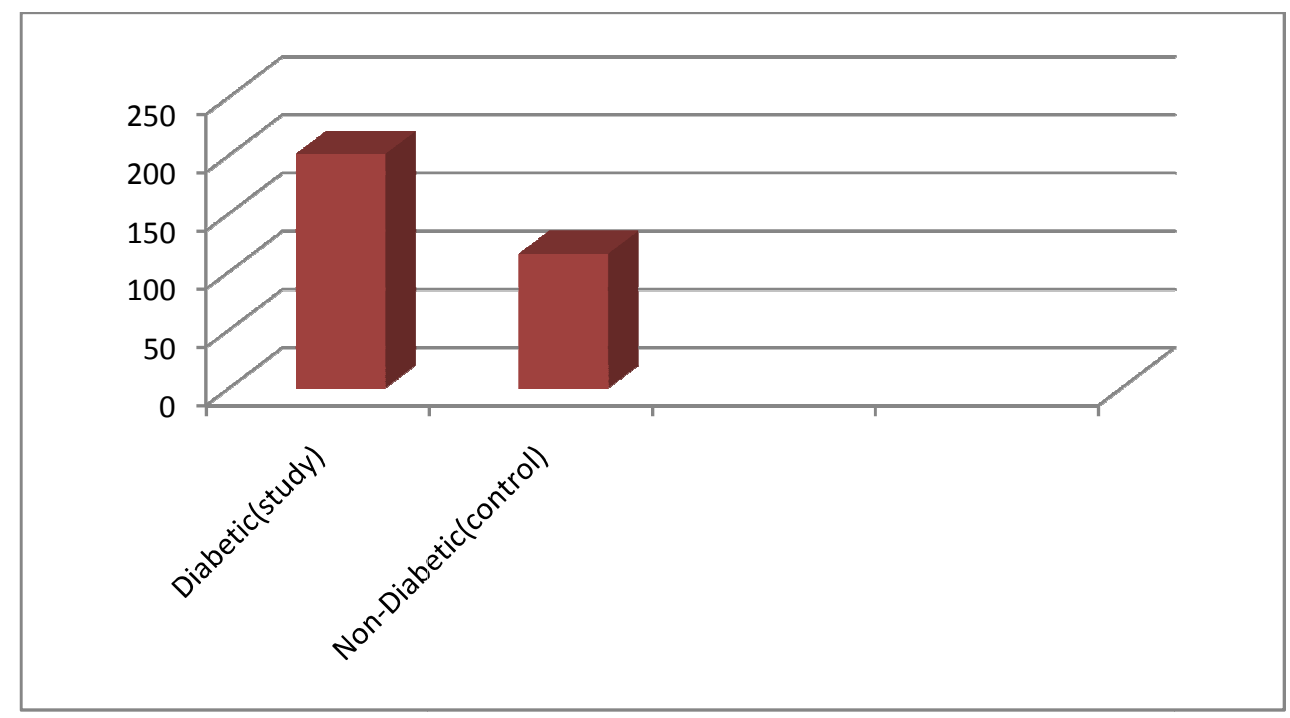


Figure-6. Diagram represents serum HDL-C (mg/dl) level in diabetic (study) and non-diabetic (control) group.

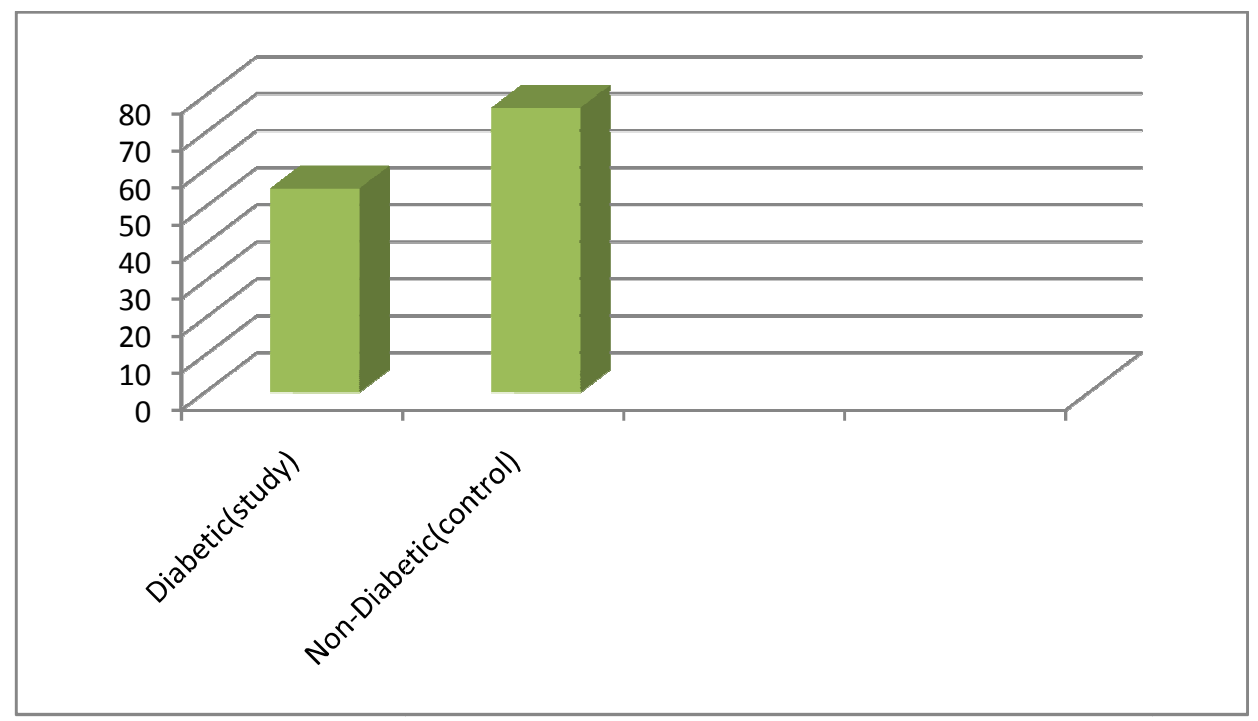

Figure-7 Diagram represents serum LDL-C (mg/dl) level in diabetic (study) and non-diabetic (control) group.

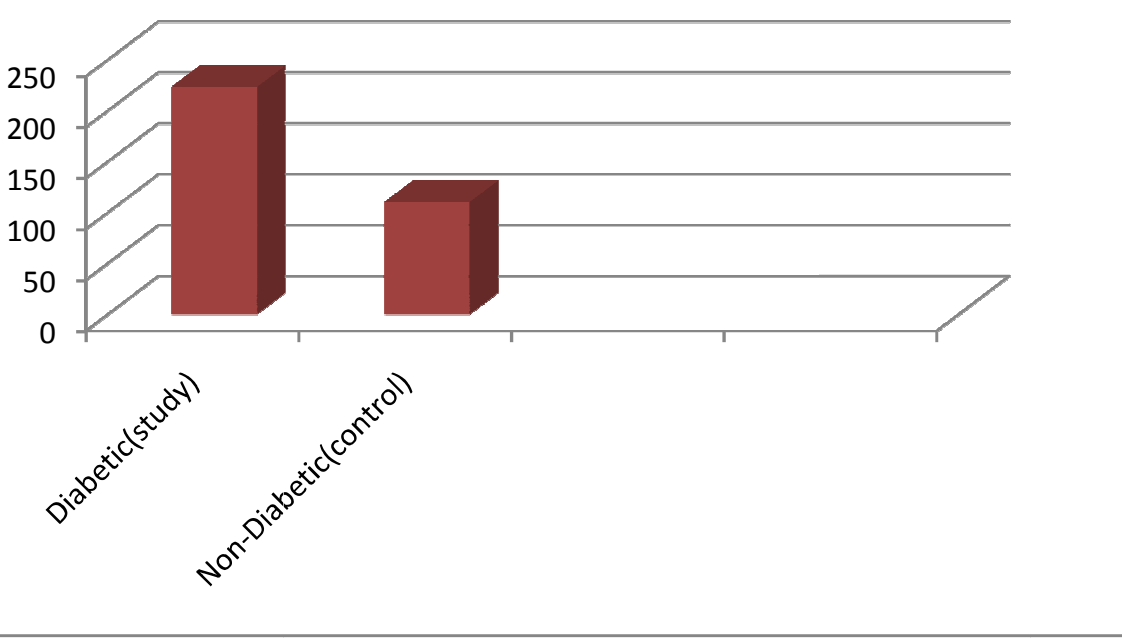

DISCUSSION: Diabetes is the most frequently found diseases worldwide and the presence of microalbumin in 24 hours urine is significant because it makes an indication towards diabetic nephropathy and this will eventually lead to end stage renal diseases (ESRD) $(5,4)$.The pathophysiological changes are identical in type 1 and type 2 diabetes. The main changes glomeruli, rarely in renal tubules (6).

In our study it has been established that 24 hours microalbumin level in urine in diabetic is higher than control.Table- 1 shows the mean of microalbumin in 24 hours urine in diabetic is higher than control group. The results obtained was compared by Fisher's unpaired 
"t-test" where computed t-value(3.91) is greater than the critical t-value(3.56).Microalbumin level in 24 hours urine in diabetic is significantly higher than control groups where the p-value was $<0.001$. In our study the prevalence of microalbuminuria is $32.3 \%$. The prevalence of microalbuminuria in male is $37.5 \%$ and in female $62.5 \%$.The microalbuminuric patients are older and had a longer duration of diabetes compared with non-albuminuric patients(7).Figure1 represents the significant elevation of 24 hours urine microalbumin in diabetic compared with non-diabetic. The rise of 24 hours urine microalbumin in diabetic suggests structural damage of glomerulus with or without pathological alteration of renal tubules.(8).

The serum creatinine in diabetic is raised significantly as compared with non-diabetic, where computed t-value (7.01) is greater than the critical t-value(2.02).High creatinine level in diabetic is due to extensive muscle damage (9) and figure-2 represents the moderate increase of serum creatinine in diabetic study group. Microalbumin/creatinine ratio is also grossly altered in diabetic study group as compared with non-diabetic control, where p-value was $<0.001$ and this is significant (table-3).High ratio of microalbumin and creatinine is due to more excretion of microalbumin in diabetic study group (10).

In our study, triglycerides, total cholesterol and LDL-C are significantly higher in diabetic subjects compared with non-diabetic individuals. In diabetes mellitus (Figure-5,4,7),the peripheral utilization of sugar is impaired following low plasma and tissue concentration of insulin(11) as a result there is increased lipolysis and decreased re-esterification takes place ,which increases plasma free fatty acids. The activity of lipoprotein lipase is low in diabetic subjects, consequently the plasma level of VLDL,LDL-C, triglycerides are increased(3,4).The HDL-C in diabetic study group is decreased significantly(Table-6) as compared with nondiabetic control and the p-value was $<0.001$.

CONCLUSION: The major microvascular complications in both type1 and type2 diabetes is Diabetic nephropathy and microalbuminuria is the earliest clinical marker. It is also a risk factor for development of macrovascular complications including atherosclerosis, myocardial infarction, cerebrovascular accident (CVA) and peripheral vascular diseases. Estimation of microalbumin at regular interval in known diabetic optimizes blood glucose control and management of dyslipidaemia and can slow the progression of nephropathy to end stage renal diseases (ESRD).Further study on more number of diabetic individual may explore a new dimension of knowledge, and is necessary to stabilize the deleterious microvascular changes to elongate life span.

\section{REFERENCES:}

1. Wild S,Roglic G,Green A,Sicree R.,King H.,Global prevalanceof diabetes; estimates for the years 2000 and projections for 2030"Diabetes Care 2004 May;27(5):1047-53.

2. Mohan V,Sandeep S,Deepa R,Saha B,Verghese C.Epidemiology of type 2 diabetes:Indian scenario,Indian Journal of Medical Research 2007 March;125:217-230.

3. Devid B,Burtis CA,Ashwood ER,Border BG,Tietz Fundamental of Clinical Chemistry.Saunders, Philadelphia, $1^{\text {st }}$ edition 2006;pp 427-461.

4. Chakraborty P,Chakraborty G,Estimation of Lipid ana Lipoproteins In:Chakraborty.P.,Chakraborty.G.(Eds),Practical pathology,New Central Book Agency,Calcutta,1 $1^{\text {st }}$ edition 1998; pp 348-352.

5. Tierney LM,McPhee SJ, Papadakis MA,Current medical diagnosis and treatment. International edition.New York,Lange Medical Books/McGraw Hill pp 1203-1215. 
6. Beckman Coulter Synchronex system kit, Chemistry information Sheet MA(Microalbumin);September 2008.

7. Nelaz E,Gjata M,Lilaj I,Burazeri G,Sadiku E,Collaku L,Bare 0,Tase M,Factors of cardiovascular risk in patients with type2 diabetes and incipient nephropathy:Hippokratia. 2008 Oct;12(4):221-224.

8. Araki S,Haneda M,Koya D,Kashiwagi A,Uzu T,Kikkawa R.Clinical impact of reducing microalbuminuria in patients with type2 diabetes mellitus.Diabetes Res Clin Prac.2008 Nov13;82 Suppl 1:S54-58..

9. Somani BL,Saha TK,Arora MM,Sharma YV,Modified bromophenol blue dye binding method for quantitation of microalbuminuria in diabetes mellitus.Medical Journal Armed Forses India.1995 Apr;51(20;110-116.

10. Therese T,Nita F,Paul McKeigue and Nish Chaturvedi,Hyperinsulinemic Microalbuminuria Circulation.1995;91:831-837.

11. Buggy D,Feely J,Murphy J,Sullivan CO,Walsh M,Microalbuminuria and coronary heart dieases in non-diabetics.Postgrad Med J.1993 Septmber;69(815):704-707.

12. Midha V,Khurana SB,Khaira NS,Narang APS et.al.Microalbuminuria in non-insulin dependent diabetes mellitus;one year follow up.Indian Journal of Nephrology.1997 OctDec; 7(4):160-163 